\title{
Nullipar Gebelerde İnkontinans Prevalansı ve Risk Faktörlerinin Değerlendirilmesi
}

\author{
Evaluation of Incontinence Prevalence and Risk Factors \\ in Nulliparous Pregnant Women
}

\author{
Hilal Uslu Yuvaci ${ }^{1}$, Mehmet Musa Aslan ${ }^{2}$, Nimet Yerli², Arif Serhan Cevrioğlu ${ }^{1}$ \\ ${ }^{1}$ Sakarya Üniversitesi Tip Fakültesi Kadın Hastalıkları ve Doğum AD. \\ ${ }^{2}$ Sakarya Üniversitesi Eğitim Araştırma Hastanesi Kadın Hastalıkları ve Doğum AD. \\ ORCİD \\ Hilal Uslu Yuvacı https://orcid.org/0000-0001-8067-3165 \\ Mehmet Musa Aslan https://orcid.org/0000-0002-7830-5002 \\ Nimet Yerli https://orcid.org/0000-0003-4796-0909 \\ Arif Serhan Cevrioğlu https://orcid.org/0000-0002-3810-6519 \\ Yazışma Adresi / Correspondence: \\ Dr. Öğr. Üyesi Hilal Uslu Yuvacı \\ Sakarya Üniversitesi Eğitim Araştırma Hastanesi Kadın Hastalıkları ve Doğum AD., Ormanpark yanı, Merkez kampüs, 3. Kat, 54100, Sakarya \\ E-mail: hilaly@sakarya.edu.tr \\ Geliş Tarihi / Received : 10-10-2019 Kabul Tarihi / Accepted : 25-11-2019 Yayın Tarihi / Online Published: 27-12-2019
}

Yuvacı H., Aslan M.M., Yerli N., Cevrioğlu A.S., Nullipar Gebelerde İnkontinans Prevalansı ve Risk Faktörlerinin Değerlendirilmesi,

J Biotechnol and Strategic Health Res. 2019;3(2):213-218 DOİ:10.34084/bshr.631162

\footnotetext{
Öz

Amaç Üriner inkontinans (Üi) kadınları fiziksel, sosyal ve ekonomik yönden etkileyen; yaşam kalitelerini bozan yaygın bir sağlık sorunudur. Gebelik ve doğuma ek olarak anne yaşı, parite, önceki doğum öyküsü, beden kitle indeksi ve gebelik öncesi Üİ varlığı gebelikte Üİ için risk faktörleridir. Bu çalışmada nullipar gebelerde Üİ prevelansı ve risk faktörleri araștırıldı.

Gereçve 1 Mart-30 Aralık 2017 tarihleri arasında Kadın Hastalıkları ve Doğum polikliniğimize başvuran 18-45 yaș arası nullipar gebeler çalışmaya dahil edildi. Olgulara Yöntemler Uluslararası İdrar Kaçırma Konsültasyon Sorgulaması-Kısa Form ICIQ-SF(International Consultation on Incontinence Questionnaire Short Form) yüz yüze görüşme ile doldurtuldu. Olguların demografik bilgileri ve ICIQ-SF puanları değerlendirildi.

Bulgular Bu çalışmada nullipar gebelerde ÜI prevelansı \% 15,9 olarak bulundu. $>30$ yaș olanlarda ICIQ-SF toplam puanları istatistiksel olarak anlamlı düzeyde yüksek bulundu $(\mathrm{p}<0,05)$. Cocukluk çağı enürezisi ve inkontinans öyküsü olanların olmayanlara göre ICIQ-SF toplam puanları istatistiksel olarak anlamlı düzeyde yüksek bulundu $(\mathrm{p}<0,05)$. Gebelik dönemi ile ICIQ-SF toplam puanları karşılaştırıldığında, gebelik dönemi 3.trimester olanların 1.trimester olanlara göre ICIQ-SF toplam puanları istatistiksel olarak anlamlı düzeyde bulundu( $(\mathrm{p}<0,05)$.

Sonuç Bu çalışmada nullipar gebelerde Üİ prevelansı \% 15,9 olarak bulundu. Üriner inkontinans prevelansı gebelik haftası ile artmaktadır. Çocukluk çağı enüresis ve üriner inkontinans öyküsü üriner inkontinans için risk faktörüdür.

Anahtar Üriner inkontinans, risk faktörü, gebelik, nullipar, ICIQ-SF

Kelimeler

Abstract

Objective Urinary incontinence (UI) affects women physically, socially and economically; is a common health problem that deteriorates quality of life. Apart from pregnancy and delivery itself, maternal age, parity, previous birth history, body mass index and presence of pre-pregnancy UI are risk factors for UI during pregnancy. In this study, the prevalence and risk factors of UI in nulliparous pregnant women were investigated.

Nulliparous pregnant women aged between 18-45 years who were admitted to the Gynecology and Obstetrics outpatient clinics of between March 1 and December 30, 2017 were included in the study. ICIQ-SF (International Consultation on Incontinence Questionnaire Short Form) was filled with face-to-face interview. Demographic data and ICIQ-SF scores were evaluated.

Results In this study, the prevalence of UI in nulliparous pregnant women was found to be $15.9 \%$. ICIQ-SF total scores were significantly higher in patients $>30$ years ( $p<0.05$ ). The ICIQ-SF total scores of the patients with a history of childhood enuresis and incontinence were significantly higher than those without a history of incontinence ( $p<0.05)$. When ICIQ-SF total scores were compared with the gestational period, ICIQ-SF total scores of the third trimester and the first trimester were found to be statistically significant $(p<0.05)$.

Conclusion In this study, the prevalence of UI in nulliparous pregnant women was found to be $15.9 \%$. The prevalence of urinary incontinence increases with gestational week. Childhood enuresis and history of urinary incontinence are risk factors for urinary incontinence.

Keywords Urinary incontinence, risk factor, pregnancy, nullipar, ICIQ-SF
} 


\section{GIIRIŞ}

Üriner inkontinans (Üi), çoğu zaman hafife alınan, ancak bir kadını fiziksel, sosyal, ekonomik yönden etkileyen; yaşam kalitesini bozan, yaygın bir sağllk sorunudur. ${ }^{1,2} \mathrm{Ge}-$ belikte Üİ prevelansı \% 25 - 64 arasında değişmektedir. ${ }^{3,4}$ Farklı çalışmalarda nullipar gebelerde ÜI prevelansı \% 10.8 - 15.4 olarak bildirilmiştir., ${ }^{5,6}$ ÜI prevelansı özellikle gebeliğin 20. haftasından sonra artmaktadır. ${ }^{7}$

Gebelik ve doğum Üİ gelişmesi için risk faktörüdür. ${ }^{8} \mathrm{Ge}-$ belik ve doğumun fasya, ligamanlar, pelvik taban kasları ve bu kasları inerve eden, mesane boynu ve üretrayı kontrol eden sinirlerde hasara neden olarak Üİ oluşmasına katkı sağladığı düşünülmektedir. ${ }^{9}$ Ayrıca hormonal değişiklikler ve ilerleyen haftalarda genişleyen uterustan mesaneye uygulanan bası nedeniyle geliştiği düşünülmektedir. ${ }^{10} \mathrm{Ge}$ beliğin kendisi dışında anne yaşı, parite, önceki doğum öyküsü, beden kitle indeksi (BMI) ve gebelik öncesi Üİ varlığı da gebelikte Üİ için risk faktörleridir. ${ }^{11-15}$

İstem dışı idrar kaçırma sorunu kadınlarda anksiyete, depresyon, utanma duygusu, özgüven kaybı ve cinsel fonksiyonların olumsuz etkilenmesine yol açarak yaşam kalitesi üzerine olumsuz etki göstermektedir. ${ }^{16-18}$

$\mathrm{Bu}$ çalışmada, primigravid gebeler arasında idrar kaçırma prevalansının, potansiyel risk faktörlerinin ve inkontinansın yaşam kalitesine etkisinin değerlendirilmesi amaçlandi.

\section{Yöntem}

1 Mart-30 Aralık 2017 tarihleri arasında Kadın Hastalıkları ve Doğum polikliniklerine başvuran 18-45 yaş arası nullipar gebeler çalışmaya dahil edildi. Çalışma için Tip Fakültesi Etik kurulundan onay alındı. (proje numaras1:71522473/050.01.04/30) Bir veya daha fazla sayıda doğum yapmış, herhangi bir obstetrik risk faktörü taşıyan ve çoğul gebeliği olanlar çalışma dışı bırakıldı. Çalışmaya katılmayı kabul eden tüm gebelere araştırmacılar tarafından hazırlanan demografik özellikleri ve risk faktörlerini sor- gulayan anket formu ile birlikte Uluslararası İdrar Kaçırma Konsültasyon Sorgulamasi-Kısa Form ICIQ-SF (International Consultation on Incontinence Questionnaire Short Form) yüz yüze görüşme ile doldurtuldu. ICIQ-SF Avery ve ark. tarafından idrar kaçırma sorununu tanımlama, sıklığı, niteliği ve ve idrar kaçırmanın yaşam kalitesine etkisini değerlendirmek amacıyla geliştirilmiştir. ${ }^{19}$ Çetinel ve ark. tarafından Türkçe geçerlik-güvenirliği yapılmış olan bu form 6 soruluk, kısa, kolay anlaşılabilir ve uygulanabilir bir sorgulama formudur.20 Toplam ölçek puanı 0-21 arasındadır. İdrar kaçırmanın ciddiyetine göre sınıflandırıldığında, 0 puan (hiç kaçırmıyor), 1-5 puan (hafif derece), 6-12 puan (orta derece), 13-18 puan (ciddi derece) ve 1921 puan (çok ciddi derece) olarak değerlendirilir. İdrar kaçıran kadınların yaşadıkları rahatsızlığın derecesini ayırmada kullanılan kesme değeri Türk kadınları için ICIQ-SF toplam ölçek puanına göre 8 olarak bildirilmiştir ( $<8$ puan rahatsızlık düzeyi az ve $\geq 8$ puan rahatsızlık düzeyi fazla).

\section{İstatistiksel Analiz}

Veriler IBM SPSS Statistics 22 programına aktarılarak tamamlanmıştır. Çalışma verileri değerlendirilirken sayısal değişkenler için tanımlayıcı istatistikler (ort, std sapma, medyan, minimum, maksimum), kategorik değişkenler için frekans dağılımları (sayı, yüzde) verilmiştir. İki bağımsız grup arasında fark olup olmadığına değişkenlerin normal dağılıma uygunluk göstermesi durumuna göre Mann Whitney U testi veya bağımsız örneklem $t$ testi ile, ikiden fazla bağımsız grup arasında fark olup olmadığına Kruskal Wallis testi veya One Way ANOVA testi ile bakıldı. Ölçek güvenirlikleri için ise ölçek güvenilirliğinin değerlendirilmesi sırasında en sık kullanılan kriterlerden biri içsel tutarlılık ölçüsü olan Cronbach’s alfadır. ICIQ-SF ölçeği için hesaplama yapılmış, Cronbach’s alfa değeri 0,86 olarak bulundu.

\section{Bulgular}

Çalışma 271 hasta üzerinden gerçekleştirilmiştir. Araştırmaya katılan gebelerin yaş ortalaması $26,02 \pm 5,05$ idi. $\mathrm{Bu}$ çalışmada nullipar gebelerde Uİ prevelansı \% 15.9 olarak 
bulundu. Katılımcıların \%68,6'sı 20-30 yaş aralığında, $\% 39,5^{\prime}$ inin eğitim düzeyi ortaokul-lise seviyesinde, \%70,8'i ev hanımı, \%42.1'i normal kiloda, \%72,3'ü hiç sigara içmemiş, \%31'i haftada birkaç kez kafein tüketiyor, \%90'ı çocukluk çağında enürezis geçirmemiş ve \%84,1'inin inkontinans öyküsü bulunmamakta idi. Katılımcıların obstetrik özellikleri incelendiğinde, \%39,1'i gebeliğin II. Trimesterinde, \%83,8'inin düşük veya kürtaj öyküsü bulunmamakta, ve \%78,9'unun gebelikte idrar kaçırma şikayeti bulunmamakta idi (Tablo 1).

\begin{tabular}{|c|c|c|c|}
\hline \multicolumn{4}{|c|}{$\begin{array}{l}\text { Tablo 1. Katılımcıların Sosyodemografik ve Obstetrik Özelliklerinin } \\
\text { Dağılımı }(n=271)\end{array}$} \\
\hline \multicolumn{2}{|c|}{ SOSYODEMOGRAFİK ÖZELLİKLER } & Min-Max & Ort $\pm S S$ \\
\hline \multicolumn{2}{|l|}{ Yaş (y1l) } & $16-41$ & $26,02 \pm 5,05$ \\
\hline & & $\mathrm{n}$ & $\%$ \\
\hline \multirow{3}{*}{ Yaş } & $<20$ & 32 & 11,8 \\
\hline & $20-30$ & 186 & 68,6 \\
\hline & $>30$ & 53 & 19,6 \\
\hline \multirow{3}{*}{ Eğitim } & İlköğretim & 105 & 38,7 \\
\hline & Ortaokul-Lise & 107 & 39,5 \\
\hline & Üniversite & 59 & 21,8 \\
\hline \multirow{2}{*}{$\begin{array}{l}\text { Çalışma } \\
\text { durumu }\end{array}$} & Ev Hanımı & 192 & 70,8 \\
\hline & Çalışıyor & 79 & 29,2 \\
\hline \multirow{3}{*}{$\begin{array}{l}\text { Sigara İçme } \\
\text { Öyküsü }\end{array}$} & Gebelik öncesi içiyordum & 42 & 15,5 \\
\hline & İçmeye devam ediyorum & 33 & 12,2 \\
\hline & Hiç içmedim & 196 & 72,3 \\
\hline \multirow{4}{*}{$\begin{array}{l}\text { Kafeinli İçecek } \\
\text { Tüketme } \\
\text { Öyküsü }\end{array}$} & Hiç tüketmiyorum & 69 & 25,5 \\
\hline & Yllda birkaç kez tüketiyorum & 70 & 25,8 \\
\hline & $\begin{array}{l}\text { Haftada birkaç kez tüketi- } \\
\text { yorum }\end{array}$ & 84 & 31,0 \\
\hline & Hergün tüketiyorum & 48 & 17,7 \\
\hline \multirow{2}{*}{$\begin{array}{l}\text { Çocukluk } \\
\text { Çağı Enürezis } \\
\text { Öyküsü }\end{array}$} & Var & 27 & 10,0 \\
\hline & Yok & 244 & 90,0 \\
\hline \multirow{2}{*}{$\begin{array}{l}\text { İnkontinans } \\
\text { Öyküsü }\end{array}$} & Var & 43 & 15,9 \\
\hline & Yok & 228 & 84,1 \\
\hline \multirow{4}{*}{ BKİ } & 18.5 ve alt 1 & 3 & 1,1 \\
\hline & 18.6-24.9 Normal kilo & 114 & 42,1 \\
\hline & $25.0-29.9$ preobez & 100 & 36,9 \\
\hline & 30 ve üzeri obez & 54 & 19,9 \\
\hline \multirow{3}{*}{ Gebelik Haftası } & 1. Trimester & 62 & 22,9 \\
\hline & 2.Trimester & 106 & 39,1 \\
\hline & 3.Trimester & 103 & 38,0 \\
\hline
\end{tabular}

\begin{tabular}{|l|l|l|l|}
\hline $\begin{array}{l}\text { Düşük/Kürtaj } \\
\text { Öyküsü }\end{array}$ & Var & 44 & 16,2 \\
\cline { 2 - 4 } & Yok & 227 & 83,8 \\
\hline $\begin{array}{l}\text { Gebelikte İdrar } \\
\text { Kaçırma }\end{array}$ & Var & 56 & 21,1 \\
\cline { 2 - 4 } & Yok & 209 & 78,9 \\
\hline
\end{tabular}

Katılımcıların ICIQ-SF toplam puanları incelendiğinde

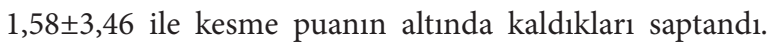
Katılımcıların sosyodemografik ve obstetrik özellikleri ile ICIQ-SF toplam puanları karşılaştırıldığında, eğitim düzeyi, çalışma durumu sigara/ kafeinli içecek tüketme öyküsü, BKİ ve düşük/kürtaj öyküleri ile ICIQ-SF toplam puanları arasında istatistiksel olarak anlamlı bir fark saptanmadı ( $\mathrm{p}>0.05)$. Yaş aralı̆̆ 1 20-30 ile $>30$ yaş olan katılımcılarda istatistiksel olarak anlamlı fark saptandı. Buna göre $>30$ yaş olanlarda ICIQ-SF toplam puanları istatistiksel olarak anlamlı düzeyde yüksek bulundu $(\mathrm{p}<0.05)$. Çocukluk çağı enürezisi ve inkontinans öyküsü olanların olmayanlara göre ICIQ-SF toplam puanları istatistiksel olarak anlamlı düzeyde yüksek bulundu $(\mathrm{p}<0.05)$. Gebelik dönemi ile ICIQ-SF toplam puanları karşılaştırıldığında, gebelik dönemi 3. trimester olanların 1. trimester olanlara göre ICIQ-SF toplam puanları istatistiksel olarak anlamlı düzeyde yüksek bulundu ( $\mathrm{p}<0.05)$. Aynı şekilde gebelikte idrar kaçıranların ICIQ-SF toplam puanları istatistiksel olarak anlamlı düzeyde yüksek idi $(\mathrm{p}<0.05)$ (Tablo 2).

\begin{tabular}{|c|c|c|c|}
\hline \multicolumn{2}{|c|}{ SOSYODEMOGRAFİK ÖZELLİKLER } & Min-Max & Ort $\pm S S$ \\
\hline \multicolumn{2}{|l|}{ Yaş (yıl) } & $16-41$ & $26,02 \pm 5,05$ \\
\hline & & $\mathrm{n}$ & $\%$ \\
\hline \multirow{3}{*}{ Yaş } & $<20(1)$ & $1,06 \pm 2,08$ & \multirow{3}{*}{$\begin{array}{l}X^{2}: 7,124 \\
\text { p: ,028 }\end{array}$} \\
\hline & $20-30(2)$ & $1,33 \pm 3,28$ & \\
\hline & $>30(3)$ & $2,79 \pm 4,43$ & \\
\hline \multirow{3}{*}{ Eğitim } & İlköğretim & $1,77 \pm 3,69$ & \multirow{3}{*}{$\begin{array}{l}X^{2}:, 461 \\
\mathrm{p}:, 794\end{array}$} \\
\hline & Ortaokul-Lise & $1,35 \pm 3,14$ & \\
\hline & Üniversite & $1,64 \pm 3,63$ & \\
\hline \multirow{2}{*}{$\begin{array}{l}\text { Çalışma } \\
\text { durumu }\end{array}$} & Ev Hanımı & $1,63 \pm 3,39$ & \multirow{2}{*}{$\begin{array}{l}\text { Z: -,609 } \\
\text { p:,543 }\end{array}$} \\
\hline & Çalışıyor & $1,45 \pm 3,65$ & \\
\hline \multirow{3}{*}{$\begin{array}{l}\text { Sigara İçme } \\
\text { Öyküsü }\end{array}$} & Gebelik öncesi içiyordum & $1,22 \pm 2,98$ & \multirow{3}{*}{$\begin{array}{l}X^{2}: 3,558 \\
p: 169\end{array}$} \\
\hline & İçmeye devam ediyorum & $2,85 \pm 4,80$ & \\
\hline & Hiç içmedim & $1,44 \pm 3,26$ & \\
\hline
\end{tabular}




\begin{tabular}{|c|c|c|c|}
\hline \multirow{4}{*}{$\begin{array}{l}\text { Kafeinli } \\
\text { İçecek } \\
\text { Tüketme } \\
\text { Öyküsü }\end{array}$} & Hiç tüketmiyorum & $0,72 \pm 2,02$ & \multirow{4}{*}{$\begin{array}{l}X^{2}: 6,436 \\
p: 092\end{array}$} \\
\hline & $\begin{array}{l}\text { Yılda birkaç kez tüket- } \\
\text { iyorum }\end{array}$ & $1,38 \pm 3,29$ & \\
\hline & $\begin{array}{l}\text { Haftada birkaç kez } \\
\text { tüketiyorum }\end{array}$ & $1,98 \pm 3,99$ & \\
\hline & Hergün tüketiyorum & $2,39 \pm 4,09$ & \\
\hline \multirow{2}{*}{$\begin{array}{l}\text { Çocukluk } \\
\text { Çağı Enüre- } \\
\text { zis Öyküsü }\end{array}$} & Var & $3,04 \pm 4,34$ & \multirow{2}{*}{$\begin{array}{l}Z:-2,881 \\
\text { p:,004 }\end{array}$} \\
\hline & Yok & $1,42 \pm 3,32$ & \\
\hline \multirow{2}{*}{$\begin{array}{l}\text { İnkontinans } \\
\text { Öyküsü }\end{array}$} & Var & $7,49 \pm 3,94$ & \multirow{2}{*}{$\begin{array}{l}Z:-12,973 \\
\text { p:,000** }\end{array}$} \\
\hline & Yok & $, 46 \pm 1,87$ & \\
\hline \multirow{4}{*}{ BKİ } & 18.5 ve alt 1 & $1,67 \pm 2,89$ & \multirow{4}{*}{$\begin{array}{l}2,496 \\
\mathrm{p}:, 476\end{array}$} \\
\hline & 18.6-24.9 Normal kilo & $1,23 \pm 3,02$ & \\
\hline & $25.0-29.9$ preobez & $1,90 \pm 3,83$ & \\
\hline & 30 ve üzeri obez & $1,70 \pm 3,66$ & \\
\hline \multirow{3}{*}{$\begin{array}{l}\text { Gebelik } \\
\text { Dönemi }\end{array}$} & 1. Trimester (1) & $, 87 \pm 3,14$ & \multirow{3}{*}{$\begin{array}{l}\mathrm{X}^{2}: 7,076 \\
\mathrm{p}:, 029^{\mathrm{b} *}\end{array}$} \\
\hline & 2.Trimester (2) & $1,59 \pm 3,39$ & \\
\hline & 3.Trimester (3) & $1,99 \pm 3,67$ & \\
\hline \multirow{2}{*}{$\begin{array}{l}\text { Düșük/Kürtaj } \\
\text { Öyküsü }\end{array}$} & Var & $2,43 \pm 4,38$ & \multirow{2}{*}{$\begin{array}{l}\mathrm{Z}:-1,522 \\
\mathrm{p}: 128\end{array}$} \\
\hline & Yok & $1,41 \pm 3,24$ & \\
\hline \multirow{2}{*}{$\begin{array}{l}\text { Gebelikte } \\
\text { İdrar Kaçır- } \\
\text { ma }\end{array}$} & Var & $7,39 \pm 3,68$ & \multirow{2}{*}{$\begin{array}{l}Z:-15,404 \\
\text { p:,000** }\end{array}$} \\
\hline & Yok &, $05 \pm, 69$ & \\
\hline $\begin{array}{l}\mathrm{X}^{2} \text { : Kruskal We } \\
{ }^{*} \mathrm{p}<0.05 \quad{ }^{* *} \mathrm{p}<\end{array}$ & $\begin{array}{l}\text { s H Test, Z: Mann Wh } \\
01 \text {, a: } 2-3, \text { b: } 1-3\end{array}$ & U Test, & \\
\hline
\end{tabular}

\section{Tartışma}

Bu çalışmada nullipar gebelerde Üİ prevelansı \% 15.9 olarak bulundu. Literatürde, primigravidlerde idrar kaçırma insidansını \% 19.9, \% 34 ve \% 39.1 olarak bildiren yayınlar mevcuttur. ${ }^{14,21,22}$ Çalışmalarda Üİ tanısı ve sıklığı değerlendirme yöntemleri arasında farklılıklar bulunmaktadır. Bazı çalışmalar anket ile inkontinans sıklığını ve miktarını sorgularken diğerleri yalnızca hasta beyanı ile inkontinansın varlığı yada yokluğunu değerlendirmektedir. Bu nedenle prevelans rakamları arasında ciddi farklılılar olmaktadır. Ayrıca çalışmaya dahil edilen hasta popülasyonunda Üİ insidansı gebelik öncesi zaten yüksek ise gebelikte Üİ prevelansının yüksek olması beklenen bir durumdur.

Gebelik haftası ilerledikçe Üİ görülme olasılı̆̆ının arttığı bilinmektedir. ${ }^{23}$ Wesnes ve ark. çalışmasında nullipar gebelerde; gebelik öncesinde \% 26 olan Üİ prevelansının, gebeliğin 30. haftasında \% 48'e çıktığını rapor etmişlerdir.6 Sharma ve ark. Üİ prevelansını gebeliğin ilk trimesterinde
\% 24.1, ikinci trimesterde \% 23.6 ve üçüncü trimesterde \% 27.9 olarak bulmuşlardır. ${ }^{4}$ Kocaöz ve ark. çalışmasında ÜI prevelansını ilk trimesterde \% 2.8, ikinci trimesterde \% 8.5 ve üçüncü trimesterde $\% 87.7$ olarak bildirmişlerdir. ${ }^{24}$ $\mathrm{Bu}$ çalışmada gebelik dönemi ile ICIQ-SF toplam puanları karşılaştırıldığında, gebelik dönemi 3. trimester olanların 1. trimester olanlara göre ICIQ-SF toplam puanları yüksek bulundu $(\mathrm{p}<0,05)$.

Gebelikte Üİ prevelansının kadın yaşı ile arttığı bildirilmiştir. ${ }^{6,25,26}$ Rortveit ve ark. EPINCONT çalışmasında, ilk doğum anındaki maternal yaşın, ilk doğum sırasındaki genç kadınlara kıyasla, 25 yaş ve üzerindeki kadınlarda UI prevalansının anlamlı olarak daha yüksek olduğunu göstermiştir. ${ }^{27} \mathrm{Bu}$ çalışmada da literatürle uyumlu olacak şekilde 30 yaşın üzerinde olanlarda ICIQ-SF toplam puanları yüksek bulundu.

Brown ve ark. nullipar gebelerde Üİ risk faktörlerini değerlendirdikleri çalışmalarında gebelik kaybı öyküsü, gebelik öncesi yüksek BKI (BKI $\geq 30 \mathrm{~kg} / \mathrm{m} 2$ ), çocukluk çağında enürezis öyküsünün nullipar gebelerde Üİ gelişimi için risk faktörü olduğunu bildirmişlerdir. ${ }^{28,29}$ Bizim çalı̧mamızda ise BKİ ve düşük/kürtaj öyküleri ile ICIQSF toplam puanları arasında istatistiksel olarak anlamlı bir fark saptanmazken ( $p>0.05)$, çocukluk çağı enürezisi ve inkontinans öyküsü olanların olmayanlara göre ICIQ-SF toplam puanları istatistiksel olarak anlamlı düzeyde yüksek bulundu $(\mathrm{p}<0.05)$.

Fazla miktarda kafeinli içecek tüketiminin Üİ için risk faktörü olduğu bilinmektedir. Ancak düşük miktarda tüketimin etkisi olmadığı düşünülmektedir. ${ }^{30}$ Yapılan metaanalizde kafein tüketiminin Üİ gelişimi için risk faktörü olmadığı gösterilmiştir. ${ }^{31} \mathrm{Bu}$ çalışmada metaanalizle uyumlu olarak kafein tüketiminin Üİ için risk faktörü olmadığı bulundu( $>>0,05)$.

Gebelikte idrar kaçırmanın kadınların yaşam kalitesini azalttığı bilinmektedir. Koçak ve ark. Türkiyede yaptıkları çalışmada Üİ şikayeti olan kadınların \% 87.2’ si idrar ka- 
çırmanın yaşam kalitelerini düşürdüğünü belirtmişlerdir.2 Dolan ve ark. primigravid gebeleri kapsayan çalışmalarında gebelikte \% 71.1 kadının yaşam kalitesi ölçek puanı düşük bulunmuştur. ${ }^{32}$ Kocaöz ve ark. gebelikte ÜI'nin kadınların yaşam kalitelerini etkilemediğini ya da çok az etkilediğini bildirmişlerdir. ${ }^{24} \mathrm{Bu}$ çalışmada hastaların yaşam kaliteleri ayrı bir ölçek ile değerlendirilmedi. Ancak, idrar kaçırmanın yaşamlarını ne kadar etkilediği konusunda bilgi veren ICIQ-SF formu dolduruldu. Bizim çalışmamızda da literatür ile uyumlu olarak gebelikte idrar kaçıranların ICIQ-SF toplam puanları yüksek bulundu ( $<<0.05)$.

\section{Sonuç}

Üriner inkontinans gebelikte sık görülen, gebelik haftası ile artan yaşam kalitesini etkileyen bir durumdur. İleri yaş, çocukluk çağı enüresis ve üriner inkontinans öyküsü risk faktörlerindendir. Antenatal bakım hizmeti veren sağlık personelinin sıklıkla görülen bu durum ile ilgili olarak farkındalığının arttırılması gerekmektedir. 
Journal of BSHR 2019;3(3):213-218

YUVACI, ASLAN, YERLi், CEVRIOĞLU. Gebelik ve Üriner İnkontinans

\section{Kaynaklar}

1. Norton P, Brubaker L. Urinary incontinence in women. Lancet. 2006;367(9504):57-67. Review.

2. Kocak I, Okyay P, Dundar M, et al. Female urinary incontinence in the west of Turkey: prevalence, risk factors and impact on quality of life. Eur Urol. 2005;48(4):634-41

3. Bø K, A H Haakstad L, Voldner N. Do pregnant women exercise their pelvic floor muscles? Int Urogynecol J Pelvic Floor Dysfunct. 2007;18(7):733-6.

4. Sharma JB, Aggarwal S, Singhal S, et al. Prevalence of urinary incontinence and other urological problems during pregnancy: a questionnaire based study. Arch Gynecol Obstet. 2009;279(6):845-51. doi: 10.1007/s00404-008-0831-0.

5. Brown S, Donath S, MacArthur C, et al. Urinary incontinence in nulliparous women before and during preg- nancy: prevalence, incidence, and associated risk factors. Int Urogynecol J. 2010;21(2):193-202.

6. Wesnes SL, Rortveit G, Bo K, et al. Urinary incontinence during pregnancy. Obstet Gynecol. 2007;109(4):922-8.

7. Højberg KE, Salvig JD, Winsløw NA, et al. Urinary incontinence: prevalence and risk factors at 16 weeks of gestation. Br J Obstet Gynaecol. 1999;106(8):842-50.

8. Gyhagen M, Akervall S, Molin M, et al. The effect of childbirth on urinary incontinence: a matched cohort study in women aged 40-64 years. Am J Obstet Gynecol. 2019;221(4):322. e1-322.e17. doi: 10.1016/j.ajog.2019.05.022.

9. Mason L, Glenn S, Walton I, et al. The prevalence of stress incontinence during pregnancy and following delivery. Midwifery. 1999;15(2):120-8.

10. Wijma J, Weis Potters AE, de Wolf BT, et al. Anatomical and functional changes in the lower urinary tract during pregnancy. BJOG 2001;108(7):726-32

11. Martins G, Soler ZASG, Cordeiro JA, et al. Prevalence and risk factors for urinary incontinence in healthy pregnant Brazilian women. Int Urogynecology J. 2010;21(10):1271-7.

12. Tas N, Uysal M. Urinary incontinence among pregnant Turkish women. Pak J Med Sci. 2011;27(3):586-590.

13. Dinç A. Prevalence of Urinary Incontinence During Pregnancy and Associated Risk Factors. Low Urin Tract Symptoms. 2018;10(3):303-307. doi: 10.1111/luts.12182.

14. Hvidman L, Foldspang A, Bugge Nielsen J. Correlates of urinary incontinence in pregnancy. Int Urogynecology J. 2002;13(5):278-83.

15. Almousa S, Bandin van Loon A. The prevalence of urinary incontinence in nulliparous adolescent and middle-aged women and the associated risk factors: A systematic review. Maturitas. 2018;107:78-83. doi:10.1016/j.maturitas.2017.10.003.

16. Lin YH, Chang SD, Hsieh WC, et al. Persistent stress urinary incontinence during pregnancy and one year after delivery; its prevalence, risk factors and impact on quality of life in Taiwanese women: An observational cohort study. Taiwan J Obstet Gynecol. 2018;57(3):340-345.

17. Rogers RG, Ninivaggio C, Gallagher K, et al. Pelvic floor symptoms and quality of life changes during first pregnancy: a prospective cohort study. Int Urogynecol J. 2017;28(11):17011707. doi:10.1007/s00192-017-3330-7.

18. O'Donnell M, Lose G, Sykes D, et al. Help-seeking behaviour and associated factors among women with urinary incontinence in France, Germany, Spain and the United Kingdom. Eur Urol. 2005;47(3):385-92; discussion 392.
19. Avery K, Donovan J, Peters JT, et al. ICIQ: A brief and robust measure for evaluating the symptoms and impact of urinary incontinence. Neurourology and Urodynamics. 2004;23(4):322-30. https://doi.org/10.1002/nau.20041.

20. Çetinel B, Demirkesen O, Yalçin O, et al. Hidden female urinary incontinence in urology and obstetrics and gynecology outpatient clinics in Turkey: What are the determinants of bothersome urinary incontinence and help seeking behavior? Int Urogynecol J Pelvic Floor Dysfunct. 2007;18(6):659-64. https://doi.org/10.1007/s00192-006-0223-6.

21. Abdullah B, Ayub SH, Mohd Zahid AZ, et al. Urinary incontinence in primigravida: the neglected pregnancy predicament. Eur J Obstet Gynecol Reprod Biol. 2016;198:110-115. doi: 10.1016/j.ejogrb.2016.01.006.

22. Solans-Domènech M, Sánchez E, Espuña-Pons M; Pelvic Floor Research Group (Grup de Recerca del Sòl Pelvià; GRESP). Urinary and anal incontinence during pregnancy and postpartum: incidence, severity, and risk factors. Obstet Gynecol. 2010;115(3):618-28. doi: 10.1097/AOG.0b013e3181d04dff.

23. Martínez Franco E, Parés D, Lorente Colomé N, et al. Urinary incontinence during pregnancy. Is there a difference between first and third trimester? Eur J Obstet Gynecol Reprod Biol. 2014;182:86-90. doi: 10.1016/j.ejogrb.2014.08.035.

24. Kocaöz S, Talas MS, Atabekoğlu CS. Urinary incontinence in pregnant women and their quality of life. J Clin Nurs. 2010;19(23-24):3314-23.

25. Balik G, Güven ES, Tekin YB, et al. Lower Urinary Tract Symptoms and Urinary Incontinence During Pregnancy. Low Urin Tract Symptoms. 2016;8(2):120-4. doi: 10.1111/ luts. 12082.

26. Samuelsson EC, Victor FT, Svärdsudd KF. Five-year incidence and remission rates of female urinary incontinence in a Swedish population less than 65 years old. Am J Obstet Gynecol. 2000;183(3):568-74.

27. Rortveit $G$, Hunskaar S. Urinary incontinence and age at the first and last delivery: the Norwegian HUNT/EPINCONT study. Am J Obstet Gynecol. 2006;195(2):433-8.

28. Brown SJ, Donath S, MacArthur C, et al. Urinary incontinence in nulliparous women before and during pregnancy: prevalence, incidence, and associated risk factors. Int Urogynecol J. 2010;21(2):193-202.

29. Daly D, Clarke M, Begley C. Urinary incontinence in nulliparous women before and during pregnancy: prevalence, incidence, type, and risk factors. Int Urogynecol J. 2018;29(3):353362.

30. Baek JM, Song JY, Lee SJ, et al. Caffeine Intake Is Associated with Urinary Incontinence in Korean Postmenopausal Women: Results from the Korean National Health and Nutrition Examination Survey. PLoS One. 2016. 22;11(2):e0149311.

31. Sun S, Liu D, Jiao Z. Coffee and caffeine intake and risk of urinary incontinence: a meta-analysis of observational studies. BMC Urol. 2016;16(1):61.

32. Dolan LM, Walsh D, Hamilton S, et al. A study of quality of life in primigravidae with urinary incontinence. Int Urogynecol J Pelvic Floor Dysfunct. 2004;15(3):160-4. 